\title{
Some interactions between human platelets and glass : von Willebrand's disease compared with normal
}

\author{
J. R. O'BRIEN AND JOAN B. HEYWOOD \\ From the Portsmouth and Isle of Wight Area Pathological Service
}

SYNOPSIS If native or heparinized blood is passed slowly through a column of glass beads at room temperature, the number of platelets removed from the initial drop emerging from the column is less? than that removed from the final drop. At $4^{\circ} \mathrm{C}$. this difference disappears. If the blood is passed $\stackrel{N}{\circ}$ rapidly through such columns at room temperature fewer platelets are removed, but the initial-final $\overrightarrow{\text { or }}$ difference persists. Von Willebrand's platelets are removed normally at slow speeds; at fast speeds 0 abnormally few platelets are removed. Platelets emerging from all such columns are in aggregates. 근

On adding glass beads to normal heparinized plasma, the platelets at once become more rounded $\vec{c}_{\vec{C}}$ and after about 50 seconds' delay they aggregate: the delay and rate of aggregation can be quantitated. Aggregation occurs best at 20 to $30^{\circ} \mathrm{C}$. and is not inhibited by the addition of some enzyme inhibitors. In von Willebrand's disease all these glass-induced aggregation phenomena occur normally and ${ }^{₹}$ aggregation in response to adenosine diphosphate (ADP), serotonin creatinine sulphate (5-HT), $\vec{\bullet}$ adrenaline, collagen, and glass is also normal.

Platelets stick to a glass surface and the removal of platelets from blood exposed to glass has formed the basis of several methods of quantitating platelet adhesiveness (Wright, 1941; Moolten and Vroman, 1949; Hellem, 1960; O'Brien, 1961). Hellem's original test measured the drop in the platelet count when citrated blood was passed through a column of glass beads, and O'Brien's test was similar but used native blood. With both these methods von Willebrand's disease blood gave normal results. On the other hand, Salzman's (1963) test, which employs an apparently similar method, gives abnormal results in von Willebrand's disease. An understanding of the differences between these two test situations might throw some light on the abnormality in von Willebrand's disease. This paper then, reports a series of experiments designed to find out more about the passage of platelets through a glass bead column and reports two new platelet phenomena occurring when heparinized platelet-rich plasma is exposed to glass.

\section{MATERIALS}

The glass beads were of $0.5 \mathrm{~mm}$. diameter and were supplied by the British Glass Manufacturing Company. Before use they were washed (Hellem, 1960).

Adenosine diphosphate, sodium salt (ADP), was obtained from Sigma Chemicals, serotonin creatinine sulphate (5-HT) from Roche Products, Ltd., adrenaline

Received for publication 26 July 1966 acid tartrate from British Drug Houses, Ltd., and sodium monoiodoacetate from L. Light and Co., Ltd.

\section{METHODS}

Platelets were counted visually (Feissley and Lüdin, $\frac{\mathrm{O}}{3}$ 1949). All glassware, apart from the beads, was siliconed.

GLASS BEAD COLUMN The method was essentially that previously reported (O'Brien, 1961). The columns were $9 \mathrm{~cm}$. long and contained $2.8 \mathrm{~g}$. of beads. Five $\mathrm{ml}$. of human blood was collected into a plastic tube and a 3 control platelet count taken. One end of the tube was connected to the pump and the other end to the column. The pump pushed the blood through the column at a constant speed either 'slow' or 'fast' (Table I). The transit을

\section{TABLE I}

DELIVERY AND TRANSIT TIMES USING DIFFERENT CAMS WITHN THE STANDARD GLASS BEAD COLUMN

\begin{tabular}{|c|c|c|c|c|}
\hline Cam & $\begin{array}{l}\text { Transit Time } \\
\text { (sec. }\end{array}$ & $\begin{array}{l}\text { Volume } \\
\text { Delivered (ml.) }\end{array}$ & $\begin{array}{l}\text { Delivery Time } \\
\text { (sec.) }\end{array}$ & $\begin{array}{l}\text { Total Time } \\
\text { (sec.) }\end{array}$ \\
\hline Slow & $\begin{array}{r}13.0 \\
3.5\end{array}$ & $\begin{array}{l}5 \\
5\end{array}$ & $\begin{array}{r}73.0 \\
19.0\end{array}$ & $\begin{array}{l}86.0 \\
22.5\end{array}$ \\
\hline
\end{tabular}

time is that for the passage of the leading edge of blood@्? through the filter. A platelet count in duplicate was made 0 of the first and sometimes the subsequent, and always of the last drop emerging from the column. The difference $\overrightarrow{\mathbb{D}}$ between any one of these counts and the control expressed $\frac{\rho}{\mathbb{D}}$ as a percentage of the control count will be called the 'percentage of platelets removed' initially or finally. In 
practice often two or more plastic tubes were filled from the same venepuncture and each subjected to one of the different conditions compared.

Platelet aggregation Platelet-rich plasma (0.38 citrate or 4 or 100 units of heparin final concentration) was prepared and after warming for $3 \mathrm{~min} ., 2 \mathrm{ml}$. was put in the cuvette of a modified EEL titrator. This method was basically that of Born (1962) and O'Brien (1962). The cuvette was surrounded by a Perspex water bath at an appropriate temperature. The plasma was stirred at a constant rate and the signal, i.e., optical density, was recorded on a Honeywell recorder, and $0.7 \mathrm{~g}$., or other weight as indicated, of glass beads was poured into the cuvette. There was then in effect a two-compartment system in the closest contact: beneath the stirrer the platelet-rich plasma was exposed to stirred glass beads, while above, the plasma was swirling round in a turbulent manner. Much swirl, recorded as a tracing of wide amplitude, indicates asymmetrical platelets; a decrease in amplitude indicates a change towards greater symmetry, e.g., spheres (O'Brien and Heywood, 1966a). An increase in optical density recorded downward on the tracings indicates platelet aggregation. Other aggregating agents were tested by adding them dissolved in $0 \cdot 1 \mathrm{ml}$. of buffered saline to the stirred platelet-rich plasma.

\section{RESULTS}

THE EFFECT OF ANTICOAGULANTS AND RED CELLS It has previously been reported that fewer platelets are removed from citrated blood than from native blood and that fewer platelets are removed from plateletrich plasma than from whole blood (O'Brien, 1961).

Heparinized (3.6 $\mu / \mathrm{ml}$.) blood and platelet-rich plasma were compared with native blood obtained from the same venepuncture. Two donors and slow and fast speeds were used (Table II). It will be seen

\section{TABLE II}

FINAL PERCENTAGE OF PLATELETS REMOVED UNDER DIFFERENT CONDITIONS

\begin{tabular}{lccc} 
Speed & Native Blood & Heparinized Blood & $\begin{array}{c}\text { Heparinized } \\
\text { Platelet-rich } \\
\text { Plasma }\end{array}$ \\
\hline Slow & 71 & 73 & 14 \\
Fast & 38 & 49 & 0
\end{tabular}

that the addition of heparin to blood has no appreciable effect. Removal of the red cells from this heparinized system causes a great decrease in the number of platelets removed. These results are thus parallel to those when citrate is used as anticoagulant.

GLASS COLUMN LENGTH In a preliminary study using a slightly different method, aliquots of 11 samples of blood were passed through columns of different lengths (Fig. 1). It will be seen that increase in column length is associated with a linear increase in the proportion of platelets removed.

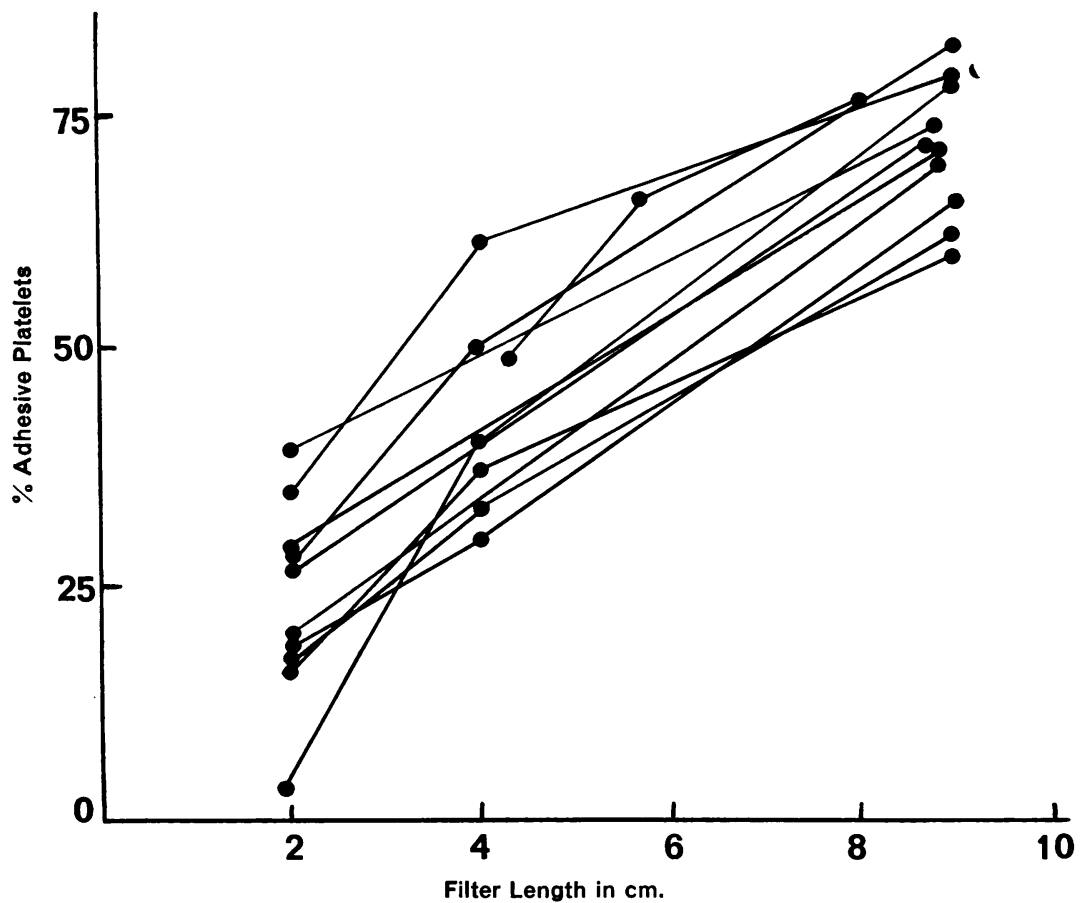

FIG. 1. The percentage of platelets removed plotted against the length of filter. Observations on aliquots of the same blood are joined. 
Using the standard method and the fast speed, aliquots of blood were passed through a standard column $(2.8 \mathrm{~g}$.) and columns four times as long $(11 \cdot 2 \mathrm{~g}$.). The mean initial figure for three experiments was $15 \%$ of platelets removed by the standard column and $44 \%$ by the long column. A four-fold increase in area results in a threefold loss of platelets. With these very long columns a trace of haemolysis was found in the emerging blood; this was never found when normal column lengths were used. With the long columns the red count was on average $1 \cdot 2$ millions/per c.mm. higher in the first drop emerging than in the untreated blood, indicating that a considerable amount of plasma, but presumably no red cells, is absorbed onto the beads. This loss of plasma from the first few drops presumably also influences the platelet count but in practice this was ignored.

SPEED OF PASSAge THROUgh THE COLUMN One aliquot of native blood was passed slowly and the other aliquot from the same venepuncture was passed fast through standard columns. Frequent counts were taken and the mean from six such studies is presented in Figure 2. With the fast speed

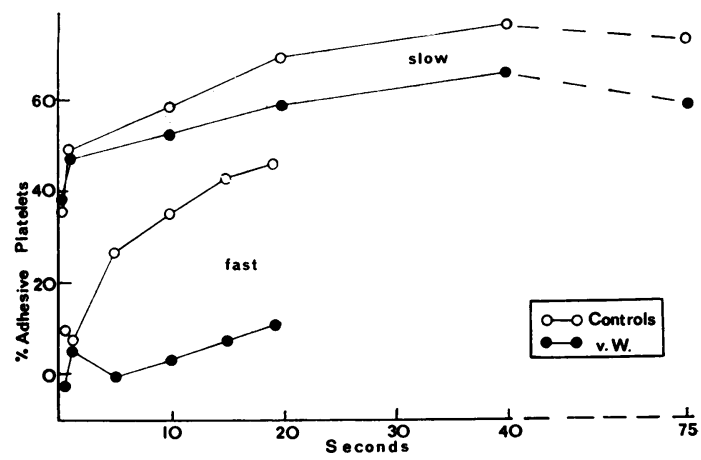

FIG. 2. The percentage of platelets removed from sequential drops emerging from the standard filters when $5 \mathrm{ml}$. of blood was passed through the standard filters at room temperature, and using either the slow or the fast speed cam. Mean values for controls and for von Willebrand's patients.

$10 \%$ of platelets are removed initially; this increases rapidly and then more slowly to reach $46 \%$ at the end of $19 \mathrm{sec}$. when all $5 \mathrm{ml}$. of blood has passed. At the slow speed, $36 \%$ of the platelets are removed initially; this increased rapidly and then remains roughly constant at about $70 \%$. The final results from these and other normals are shown individually in Figure 3.

EFFECT OF TEMPERATURE Hellem (1960) and O'Brien (1961) reported that the number of platelets removed

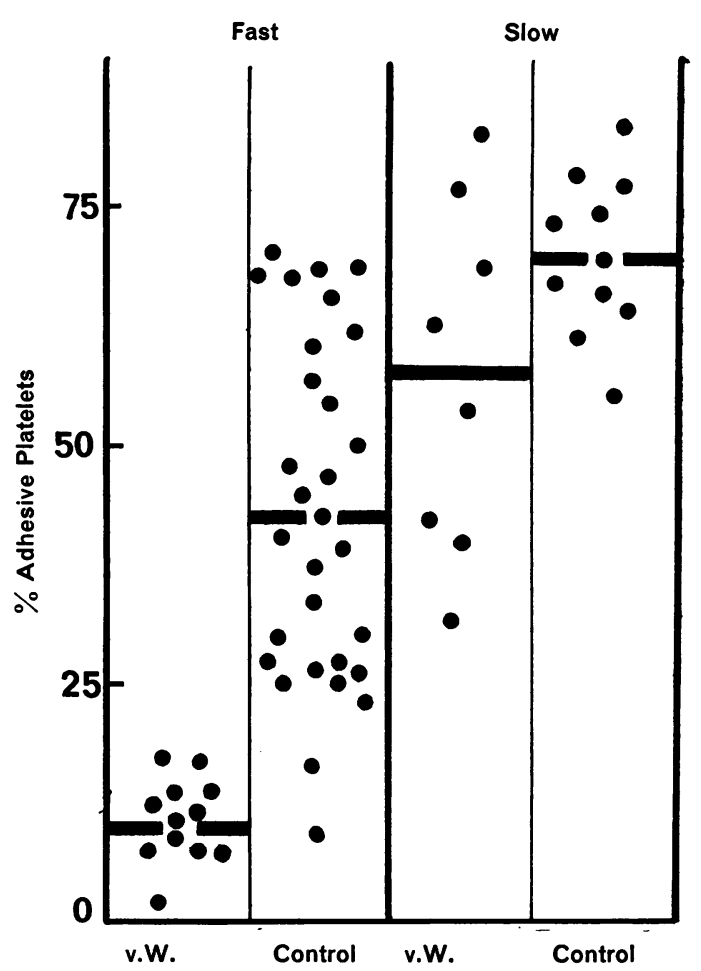

FIG. 3. Individual results of final percentage of platelets removed from control and from von Willebrand's patients using the slow and fast speed cams. The mean for each group is indicated by a horizontal bar.

from blood cooled to $4^{\circ} \mathrm{C}$. and passed slowly through a column was similar to that at room temperature, and furthermore, the initial and final figures were similar.

A number of experiments were carried out using aliquots of the same blood at slow and fast speeds and at room temperature and at 4 to $6^{\circ} \mathrm{C}$.; one such experiment is reported in Table III. The percentage $\bigcirc$ of platelets removed from the final drop compared with the initial percentage is increased at $22^{\circ} \mathrm{C}$. at both speeds but no increase occurs at $4^{\circ} \mathrm{C}$. at the

TABLE III

THE EFFECT OF SPEED OF PASSAGE AND TEMPERATURE ON PLATELET REMOVAL

\begin{tabular}{|c|c|c|c|c|c|c|}
\hline \multirow[t]{3}{*}{ Speed } & \multicolumn{2}{|l|}{$4^{\circ} \mathrm{C}$} & \multirow{3}{*}{$\frac{22^{\circ} \mathrm{C}}{\text { Initial }}$} & \multirow{3}{*}{ Final } & \multirow{2}{*}{\multicolumn{2}{|c|}{$\frac{22^{\circ} \mathrm{C} .}{\text { Average }}$}} \\
\hline & \multirow[t]{2}{*}{ Initial } & \multirow[t]{2}{*}{ Final } & & & & \\
\hline & & & & & Initial & Final \\
\hline $\begin{array}{l}\text { Slow } \\
\text { Fast }\end{array}$ & $\begin{array}{c}48 \\
3^{1}\end{array}$ & $\begin{array}{l}50 \\
12^{1}\end{array}$ & $\begin{array}{l}67 \\
18\end{array}$ & $\begin{array}{l}80 \\
80\end{array}$ & $\begin{array}{r}35 \\
9\end{array}$ & $\begin{array}{l}70 \\
42\end{array}$ \\
\hline
\end{tabular}

${ }^{1}$ Average of three experiments.

${ }^{2}$ Means derived from experiments in Fig. 3. 
slow speed. (The difference between $3 \%$ and $12 \%$ at the fast speed is not significant.) Cooling accordingly produces two effects: at slow speed many platelets were removed but the final figure showed no increase over the initial. At fast speed few platelets were removed throughout the run.

VON WILLEBRAND'S DISEASE AND HAEMOPHILIA Eight patients were studied with von Willebrand's disease (a long bleeding time, low anti-haemophilic globulin level, and a history suggesting dominant inheritance): they were not anaemic, except one whose haemoglobin was $10 \cdot 3 \mathrm{~g} . \%$. The mean results are reported in Figure 3. At slow speed they did not differ significantly from normal. At the fast speed very few platelets were removed initially; the final figure $(10 \%)$ is even more obviously abnormal. The individual final figures are reported in Fig. 3, from which it will be seen that at the fast speed there is virtually no overlap between the patients and 30 results from 17 healthy controls (mean $42.4 \%$ ).

On three occasions native blood from von Willebrand patients was passed quickly through an $11 \cdot 2 \mathrm{~g}$. column, i.e., four times as long as the normal $2 \cdot 8 \mathrm{~g}$. column. The initial mean for these runs was $22 \%$ compared with the mean of three normals which was $44 \%$. Thus although the time taken for blood to pass through the filter $(17 \mathrm{sec}$.) is longer than that using the slow speed at normal column length $(13 \mathrm{sec}$.) the difference between von Willebrand and normal blood persisted. Two patients with haemophilia were studied similarly and were not apparently different from normal.

\section{RESULTS FOR PLATELET AGGREGATION INDUCED BY GLASS}

The platelet counting fluid contains cocaine which causes platelet aggregates to disperse. However, routine blood films were made from blood emerging from the columns and sometimes this blood was fixed immediately in formol citrate and then spread; it was then found that 80 to $100 \%$ of the platelets even from the initial drop at fast speed (contact time $3.5 \mathrm{sec}$.) emerged in small clumps. Accordingly, the system described under methods was devised to study platelet aggregation induced by glass.

When $0.7 \mathrm{~g}$. of glass beads was added to stirred heparinized (3.6 or $100 \mathrm{u}$. heparin/ml.) platelet-rich plasma at $24^{\circ} \mathrm{C}$. it was found that the amplitude of the tracing decreased immediately. After a delay of about 50 seconds aggregation began and the tracing went down. A typical run is recorded in Fig. 4 and is compared with the effect of adding a suspension of tendon 'collagen'. With collagen the decrease in amplitude is delayed until just before aggregation

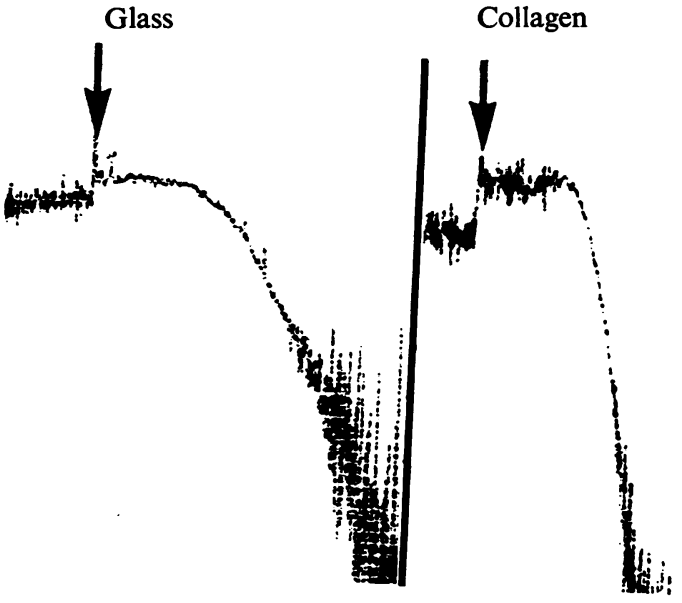

FIG. 4. Glass: heparinized platelet-rich plasma is stirred at $24^{\circ} \mathrm{C}$. and $0.7 \mathrm{~g}$. glass beads added at arrow. Collagen: heparinized platelet-rich plasma is stirred at $37^{\circ} \mathrm{C}$. and a suspension of tendon added at arrow.

occurs. With glass it occurs immediately the glass is added. This change in amplitude following the addition of glass could have been due to an alteration in the stirring due to the presence of the beads. Beads were added to stirred platelet-rich plasma and the decrease in amplitude recorded. Ten seconds later the platelet-rich plasma but not the beads was transferred to another cuvette and stirred. A small amplitude was again recorded, and the aggregation did not occur. Platelet-poor plasma was contacted with small and large amounts of glass for varying periods and these plasmas but not the beads were then added to stirred platelet-rich plasma. No change in amplitude and no aggregation occurred.

The effect of temperature was unexpected. At $37^{\circ} \mathrm{C}$. the addition of $0.7 \mathrm{~g}$. of beads to heparinized platelet-rich plasma produced minimal aggregation after a delay of about two minutes, The reaction was optimal with a short delay and rapid aggregation at $24^{\circ} \mathrm{C}$; at $15^{\circ} \mathrm{C}$. the reaction was again feeble (Fig. 5). If citrated platelet-rich plasma was compared with heparinized platelet-rich plasma, at all temperatures, the delay was longer and the degree of aggregation produced was very much less. If the rate of stirring was greatly reduced, the delay and the rate of aggregation was feeble. Increasing the stirring above an optimal rate of about 400 r.p.m. did not enhance aggregation. Increasing quantities of beads were added to $2 \mathrm{ml}$. aliquots of heparinized platelet-rich plasma at $24^{\circ} \mathrm{C} .: 0 \cdot 23 \mathrm{~g}$. of beads produced little or no effect; $0.46 \mathrm{~g}$. produced aggregation after a delay of about $60 \mathrm{sec}$; $0.7 \mathrm{~g}$. produced a more vigorous response, and $0.93 \mathrm{~g}$. sometimes interfered with the 

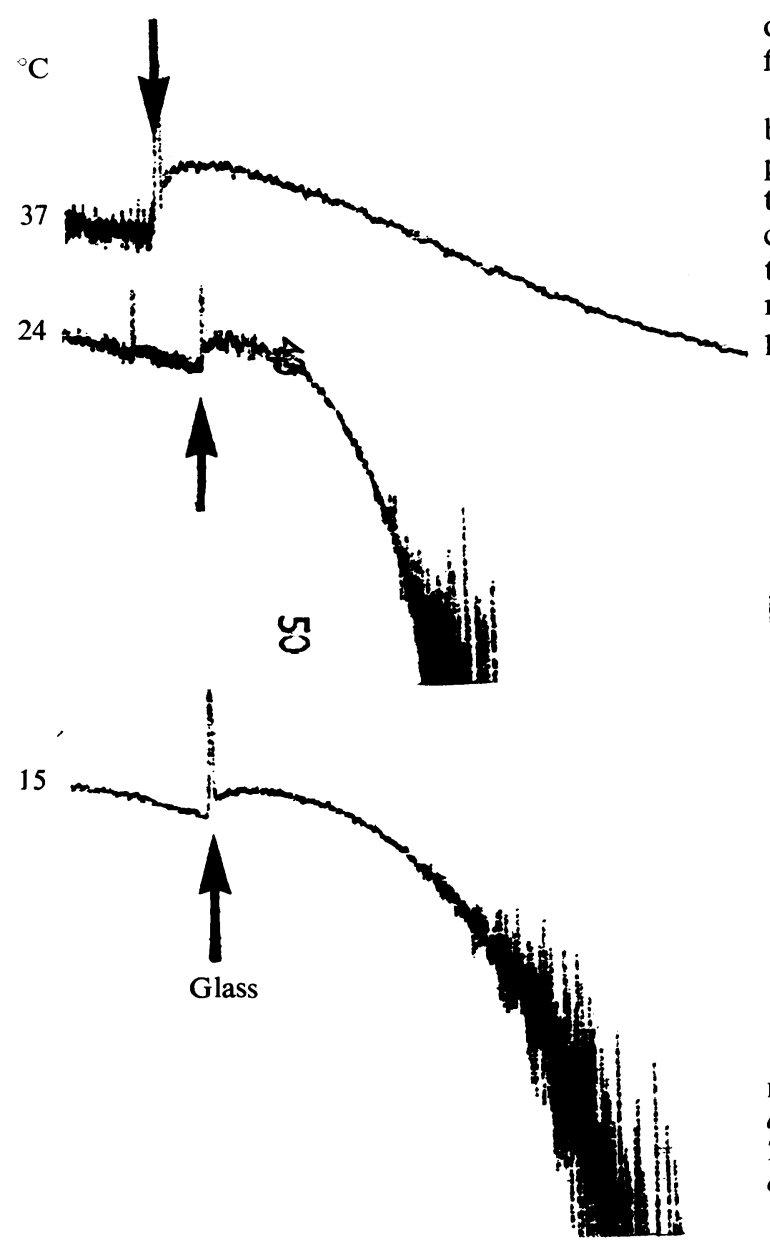

FIG. 5. Aliquots of the same platelet-rich plasma adjusted to the temperature indicated and stirred. Beads, $0 \cdot 7 \mathrm{~g} .$, added at the arrow.

rotation of the magnet and the rate of aggregation was not much increased above that with $0.7 \mathrm{~g}$.

Before the effect of varying the platelet count could be investigated a method of quantitating the response had to be devised. It was decided to define the delay as the time in seconds from the addition of beads till the tracing had descended 3 chart units. The rate of aggregation is reflected in the steepness of the tracing, but few tracings had an easily definable part of maximal steepness through which a straight line could be drawn. In practice an approximate estimate of the maximal rate of aggregation was obtained by measuring the horizontal distance the tracing traversed when it dropped from 3 to 8 chart units below the control level (Fig. 6). Thus, platelet-rich plasma which reacts vigorously with glass had a short delay and the rate of aggregation is recorded by a low figure.

The effect of altering the platelet count could now $\overrightarrow{\overrightarrow{\mathrm{S}}}$ be quantitated. Platelet-rich plasma was diluted witho platelet-poor plasma obtained from the same blood $\frac{}{0}$ to obtain platelet-rich plasma with different platelet $\frac{\bar{w}}{\bar{s}}$ counts and these mixtures were tested at $24^{\circ} \mathrm{C}$. with $ه$ the standard 0.7 g. of beads. The delay (Fig. 7) and rate of aggregation for 12 such experiments were plotted against the platelet counts. It will be seen that.

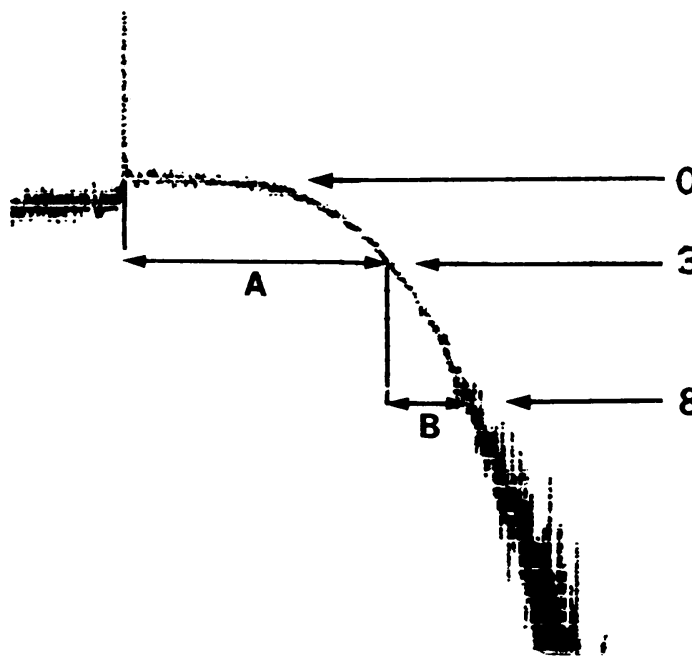

FIG. 6. Measurement of glass response tracings. $0,3, \frac{\mathrm{O}}{3}$ and 8 indicate decrease in optical density in chart units. Time $A$ in seconds is 'delay time'. Distance $B$ in sixteenths of an inch is 'rate of aggregation'.

for a given plasma the higher the platelet count the shorter the delay. Since all plasmas tested showed ac similar pattern of response on dilution it is possible 3 to compare the responses of different plasmas of known platelet count by plotting the results on the graph and following an appropriate line to an arbitrarily chosen platelet count. The count chosen was 350,000 platelets per c.mm. and the derived figure will be referred to as the 'adjusted delay' figure. $\mathrm{N}$

THE RELEASE OF AN AGGREGATING AGENT BY GLASS To platelet-rich plasma stirred at $24^{\circ} \mathrm{C}$. beads, $0.7 \mathrm{~g}$., were added: when maximal aggregation has occurred the platelet-rich plasma was immediately centrifuged $\bar{\Phi}$ at 4,000 r.p.m. for three min. and $0.5 \mathrm{ml}$. of the super-: natant added to another sample of stirred platelet-rich ${ }^{\circ}$ plasma and some aggregation occurred. If ADP 5M $\times 10^{-6}$ was added to platelet-poor plasma and the $\frac{\text { ? }}{1}$ tube treated identically, similar results were obtained:을 thus glass may liberate ADP. 


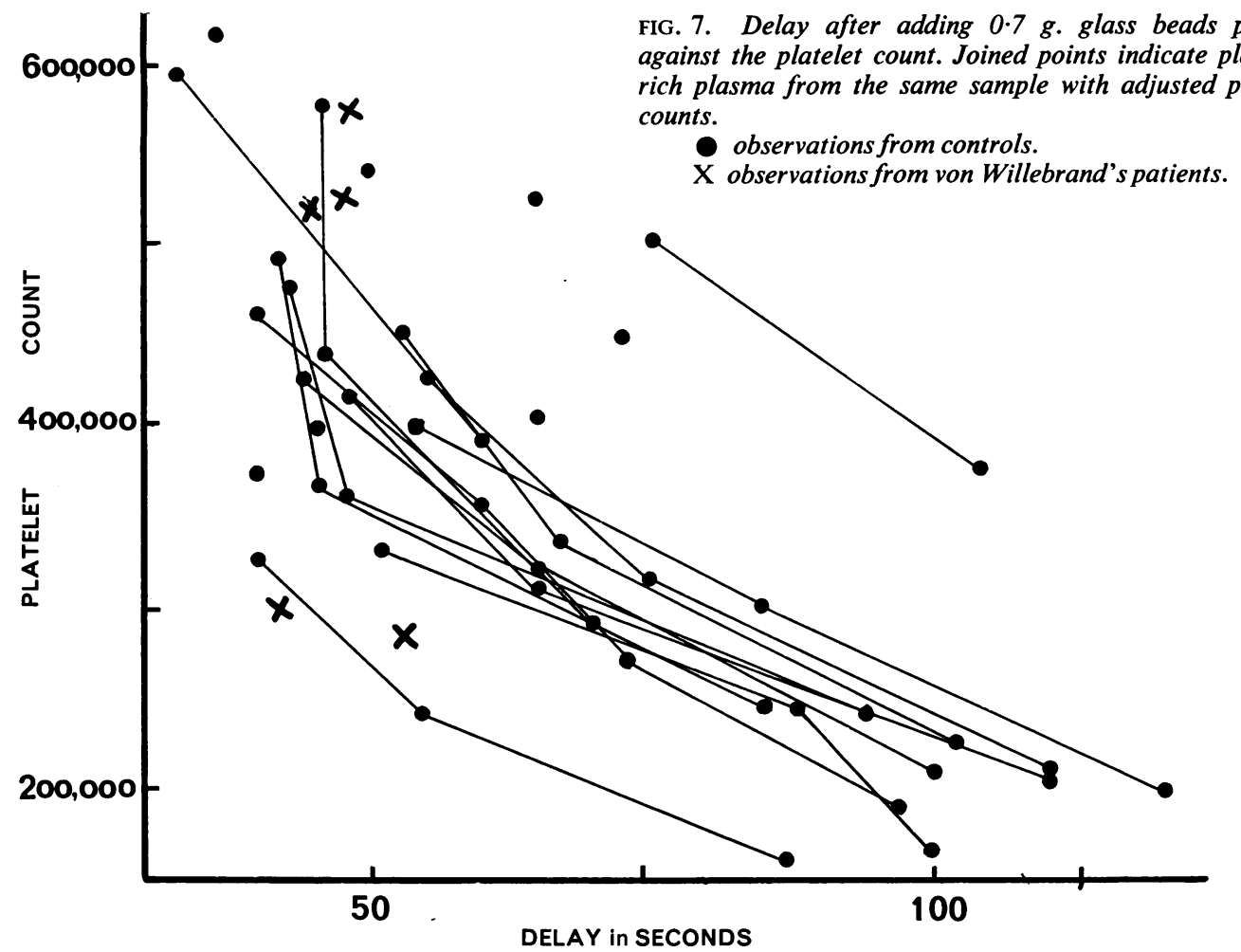

INHIBITION OF GLASS-INDUCED AGGREGATION AND SHAPE CHANGE The prior addition of $0.1 \mathrm{ml}$. adenosine $\mathrm{M} \times 10^{-2}$ or $0.1 \mathrm{ml}$. of $5 \%$ E.D.T.A. inhibited aggregation but had no effect on the shape change. Two ml. of platelet-rich plasma was incubated for 10 minutes with $0.1 \mathrm{ml}$. of each of the following enzyme inhibitors at the strength given and then the platelet-rich plasma was tested for its reaction to glass: dinitrophenol $5 \mathrm{M} \times 10^{-2}$, sodium malonate $5 \mathrm{M} \times 10^{-2}$, sodium arsenate $5 \mathrm{M} \times 10^{-3}$, sodium iodoacetate $5 \mathrm{M} \times 10^{-3}$, sodium cyanide $4 \mathrm{M} \times 10^{-2}$, and strophanthin $\mathrm{G}$ (Oubaine) $2 \mathrm{M} \times$ $10^{-2}$. None was found to inhibit aggregation or the shape change produced by glass or ADP. Incubation with iodoacetate and sodium cyanide together inhibited aggregation and the shape change induced by glass and also by ADP.

A COMPARISON OF DIFFERENT BEADS IN THE GLASS COLUMN AND IN GLASS-INDUCED AGGREGATION Throughout the experiments reported one standard sample of beads was used. Another new sample of beads was obtained and the two kinds compared in the glass columns and in the glass-induced platelet aggregation test. It was found that in both tests the new beads were markedly inferior. With standard beads $40 \%$ of the platelets were removed by the columns and with new beads $17 \%$ were removed Standard beads added to stirred platelet-rich plasma gave a delay time of $65 \mathrm{sec}$. and the new beads a time of 85 seconds.

EFFECT OF BEADS ON VON WILLEBRAND'S AND HAEMOPHILIC PLATELET-RICH PLASMA Heparinized plateletrich plasma was prepared from three patients with von Willebrand's disease, and $0 \cdot 7,0.46$, and $0.23 \mathrm{~g}$. of beads were added to aliquots of each plasma. The decrease in amplitude, the delay and the degree of aggregation with the three different amounts of glass were all similar to those obtained from normal plasmas (Table IV). The delay time results of adding $0.7 \mathrm{~g}$. of glass to these plasmas are recorded $(\mathrm{X})$ on Fig. 7 together with further isolated studies on normal plasma. The normality of all these glassinduced aggregation results in the von Willebrand's patients is in striking contrast to the abnormality found in the glass column tests, even though blood for both tests was often obtained from the same venepuncture.

The platelet-rich plasma from haemophiliacs responded similarly to that from the normal controls in the glass-induced aggregation tests. 
TABLE IV

NORMAL AND VON WILLEBRAND PLATELET-RICH PLASMA COMPARED IN GLASS AGGREGATION TEST ${ }^{1}$

\begin{tabular}{|c|c|c|c|c|c|c|}
\hline \multirow[t]{3}{*}{ Blood } & \multicolumn{3}{|c|}{ Delay Time (g.) } & \multicolumn{3}{|c|}{ Rate of Aggregation } \\
\hline & \multicolumn{3}{|c|}{ Weight of Beads } & \multicolumn{3}{|c|}{ Weight of Beads (g. } \\
\hline & 0.70 & 0.46 & 0.23 & 0.70 & 0.46 & 0.23 \\
\hline $\begin{array}{l}\text { Controls } \\
\text { von Willebrand }\end{array}$ & $\begin{array}{l}47 \\
47\end{array}$ & $\begin{array}{l}62 \\
62\end{array}$ & $\begin{array}{r}143 \\
98\end{array}$ & $\begin{array}{l}18 \\
18\end{array}$ & $\begin{array}{l}25 \\
21\end{array}$ & $\begin{array}{l}72 \\
55\end{array}$ \\
\hline
\end{tabular}

${ }^{1}$ Means from three individuals in each group.

\section{RESULTS WITH OTHER AGGREGATING AGENTS}

Platelet-rich plasma from three von Willebrand patients was tested for its response to ADP, serotonin, adrenalin, and collagen, and these results were quantitated (O'Brien and Heywood, 1966b). All these results were strictly within the normal range. An extremely active suspension of collagen was prepared that caused normal platelet-rich plasma to begin aggregating on average in 25 seconds. The average figure from three von Willebrand patients was $27 \mathrm{sec}-$ onds. Thus, with the submaximal collagen test (O'Brien and Heywood, 1966b) and with maximal stimulation, von Willebrand's disease blood was indistinguishable from normal.

\section{DISCUSSION}

Von Willebrand's disease blood has repeatedly been shown to be abnormal when passed through a column of glass beads (Zucker, 1963; Salzman, 1963; Strauss and Bloom, 1965), and it is now shown that high transit speed is essential to show up this difference. Thus, if the platelet-plasma-glass reactions were better understood, the nature of the von Willebrand abnormality might be also.

EFFECT OF GLASS COLUMN LENGTH Doubling the surface area of glass results in the removal of approximately double the number of platelets, and the simplest and probably correct explanation is that the glass surface area is directly responsible for platelet removal; but doubling the length of column also doubles the contact time. Thus the results are compatible with a reaction, smoothly progressive in time, between platelets, plasma, and glass. But from Fig. 2 the rate of removal is initially rapid and soon reaches a plateau. The activation of some clotting factor is an obvious time-dependent reaction which might mediate platelet removal; but since normal heparinized blood and haemophilic blood behave normally this seems unlikely, but is not excluded.

If a sub-population of extra-reactive platelets existed, they would have been removed first and produced disproportionately high figures in the short columns. This was not found, so these experiments lend no support to this hypothesis.

EFFECT OF FLOW SPEED AND BLOOD AND PLASMA The marked difference between blood passed slowly and $\bar{\sigma}$ fast through a column must be related to the hydro- $\overline{\bar{c}}$. dynamic differences. These forces must also be $\mathbb{\varnothing}$ widely different when blood and plasma are passed through the column and again wide differences are ${ }^{\infty}$ observed. This latter difference seems obvious if red $\overrightarrow{0}$ cells are regarded as constituting $45 \%$ by volume of $\overrightarrow{\vec{H}}$ inert particles in the blood. On the other hand, it has ${ }_{\sigma}^{\omega}$ been claimed that ADP is liberated from red cells during passage through a column of beads (Hellem, 1960). This claim is hard to prove or disprove, particularly since ADP is metabolized rapidly by $\overrightarrow{\mathrm{v}}$ plasma and platelets. It may be significant that in the very long columns when traces of haemolysis were ? found, the percentage of platelets removed was lessnot more than might have been expected. The possible relevance of ADP-like activity found after the addition of glass to platelet-rich plasma is discussed later.

EFFECT OF TEMPERATURE At $6^{\circ} \mathrm{C}$. and with the slow. speed there is no difference between the number of $O$ platelets removed initially and finally, but at room temperature there is a marked increase between the first and last drops. These findings might suggest that $\frac{0}{\square}$ initially platelets stick directly to glass. The subse- $\stackrel{0}{ }$ quent increase at room temperature may be due to $a_{\hat{O}}^{\vec{B}}$ rapid change in or around those platelets already 3 stuck so that further platelets stick to them, as has been clearly demonstrated by Salzman (1963). What-o ever the true nature of this increase it is temperaturedependant and presumably enzymatic.

GLASS-INDUCED AGGREGATION Platelet removal by

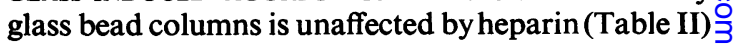
but occurs less well in citrated blood. Glass-induced platelet aggregation also occurs in heparinized? platelet-rich plasma but not in citrated platelet $\frac{\vec{O}}{O}$ rich plasma. Accordingly, it seems that a normal calcium concentration is necessary for most platelet- $N$ glass interactions (but not the shape change), and since platelet-to-platelet adhesion, i.e., aggregation, is not grossly decreased in citrate compared with in ${ }^{\omega}$ heparin, it is suggested that citrate interferes pre-dominantly with the glass-plasma protein interaction rather than with the platelet surface.

Many aggregation and disaggregation phenomena? are influenced by temperature. At $24^{\circ} \mathrm{C}$. minimal $-\frac{0}{\circ}$ amounts of ADP induce aggregation but the dis- $\frac{\mathrm{\Phi}}{\mathrm{D}}$ aggregation found at $37^{\circ} \mathrm{C}$. is suppressed; the bi- $\frac{\text { ? }}{\mathrm{O}}$ phasic adrenaline response induced at $37^{\circ} \mathrm{C} . \stackrel{2}{\circ}$ becomes at $24^{\circ} \mathrm{C}$. a single wave of aggregation. It is $?$ 
concluded that there is often a balance of processes favouring aggregation which are dominant at $24^{\circ} \mathrm{C}$. and others favouring disaggregation which are most active at $37^{\circ} \mathrm{C}$. It is conceivable that on the addition of glass at $37^{\circ} \mathrm{C}$. the disaggregation processes are immediately dominant.

It is not known whether the ADP-like activity found in the supernatant when glass-induced aggregation of platelet-rich plasma in the cuvette is complete, is the cause or the result of aggregation. If ADP is liberated early enough in the columns it could account for the appearance of aggregated platelets in the first drop of blood emerging from the columns 3.5 seconds after the blood has first touched the glass, and for the subsequent apparent increase in stickiness of the platelets. On the other hand the observation in the cuvette that aggregation, and hence the presence of ADP, could not be recorded before about 50 seconds. This might be due to differences in two techniques but the difference in time remains impressive.

The similarity of at least part of the underlying processes in the glass column technique and glassinduced aggregation is supported by the finding that a different batch of beads gave low results in both test situations.

SHAPE CHANGE INDUCED BY GLASS The decrease in amplitude occurring immediately heparinized platelet-rich plasma is exposed to glass is thought to indicate a change in shape towards more symmetrical forms. The decrease in amplitude is not due to an altered hydrodynamic situation since it persists after the glass is removed and is not due to contact activation of plasma. It is apparently due to the almost instantaneous transformation of platelets when they approach glass wetted with plasma. But it is curious that this change is complete in one to three seconds. The shape change induced by ADP, thrombin, and collagen is delayed and immediately precedes the platelets sticking together (O'Brien and Heywood, 1966a) and even occurs after the same delay under some conditions that inhibit aggregation. Thus, with ADP the shape change seems to be an independent phenomenon, but nevertheless, an essential prerequisite of sticking. On adding glass the shape change occurs immediately and aggregation occurs some 50 seconds later. This situation is clearly very different from that occurring after adding ADP, yet in the presence of E.D.T.A., both glass and ADP produce a normal change in platelet shape but no aggregation occurs. In E.D.T.A. platelet-rich plasma platelets almost certainly do not stick to glass at all, yet the shape changes.

Incubation with strong iodoacetate for a long time inhibits glass and ADP-induced aggregation. How- ever, neither cyanide alone nor iodoacetate at an appropriate strength inhibits aggregation, but together they will inhibit aggregation induced by glass or by ADP. Gorstein and Carroll (1965) report that cyanide and iodoacetate when added together inhibit potassium uptake in the human platelets. They conclude that the potassium pump can obtain energy either from respiration or from glycolysis and that both pathways have to be blocked to inhibit potassium uptake. Our findings suggest that the development of 'stickiness' may also derive energy from either of these pathways since both have to be blocked to prevent aggregation. 'Stickiness' may thus be related to the functioning of the potassium pump, and to the inhibition of water as witnessed by the volume change (Bull and Zucker, 1965) and shape change (O'Brien and Heywood, 1966a).

VON WILLEBRAND's DISEASE The results in the slow and fast speed columns are fully compatible with the failure of Hellem and O'Brien with their original relatively slow techniques to find an abnormality in von Willebrand platelets. These results also support the findings of Zucker (1963), Strauss and Bloom (1965), and Salzman (1963) that at fast speeds abnormally few von Willebrand platelets are removed. The difference between the events at slow (transit time $13 \mathrm{sec}$.) and fast (transit time $3.5 \mathrm{sec}$.) speeds are too poorly understood to permit a clear understanding of the abnormality in von Willebrand's disease. The difference is not time-dependent, since if blood is passed rapidly through a very long column (transit time $17 \mathrm{sec}$.), von Willebrand's blood is still abnormal. At slow speeds perhaps all platelets are removed more easily and the difference between von Willebrand and normal platelets, if slight, might then disappear.

Apart from the abnormal findings when studied in the glass columns von Willebrand platelets were stricly normal by all the techniques that could be devised (see especially Fig. 7). With maximal and minimal stimulation of platelet-rich plasma by adding glass, collagen, ADP, adrenaline, and serotonin, von Willebrand's platelets behaved entirely normally. The abnormally long bleeding time in von Willebrand's disease suggests a platelet abnormality and this is apparently confirmed by the abnormal results with glass bead columns. However, when the red cells are removed, the platelets in platelet-rich plasma cannot be shown to be abnormal, yet it seems inherently unlikely that the red cells are responsible for this discrepancy. The low antihaemophilic globulin also does not seem to be responsible, particularly since haemophilic blood appeared to be normal in all tests. The functional abnormality in von Willebrand's disease thus remains unexplained. 
This work was carried out during the tenure by one of us (J.R.O'B.) of grants from the Medical Research Council and the British Heart Foundation, both of which are gratefully acknowledged.

\section{REFERENCES}

Born, G. V. R. (1962). Nature (Lond.), 194, 927.

Bull, B., and Zucker, M. B. (1965). Proc. Soc. Exp. Biol. (N.Y.), $120,296$.

Feissley, R., and Lüdin, H. (1949). Rev. Hémat., 4, 481.
Gorstein, F., and Carroll, H. (1965). Personal communication. Hellem, A. J. (1960). Scand. J. clin. Lab. Invest., 12, suppl. 51.

Moolten, S. E., and Vroman, L. (1949). Amer. J. clin. Path., 19, 701. O'Brien, J. R. (1961). J. clin. Path., 14, 140.

- (1962). lbid., 15, 446. , and Heywood, J. B. (1966a). Ibid., 19, 148.

- - - (1966b). Thrombos. Diathes. haemorrh. (Stuttg.), in the press.

Salzman, E. W. (1963). J. Lab. clin. Med., 62, 724.

Strauss, H. S., and Bloom, G. E. (1965). New Engl. J. Med., 273, 171 . Wright, H. P. (1941). J. Path. Bact., 53, 255.

Zucker, M. B. (1963). Nature (Lond.), 197, 601. 